\title{
Article
}

\section{Extreme Losers}

\section{On Excess and Profitless Expenditure of Male Gamblers}

\author{
Marco Pedroni \\ eCampus University, Italy
}

\begin{abstract}
The essay looks at male gambling by investigating it as a form of resistance to the utilitarian values which lie at the base of the market logic. Excess is viewed as a central notion in opposition to that of utility. Far from minimising the negative impact of excessive gambling on society and individuals, this contribution attempts to go beyond an analysis based on the categories of pathology and expenditure. Through excess, the pathological gambler unveils the symbolic and arbitrary ideology of capitalism which sees economic success as a sign of election or a choice whereby money is used not as an investment or to access to goods and services, but 'wasted'. The article attempts to answer the following research question: How does excess manifest in male gambling practices? Risk factors for extreme gambling are analysed, with a particular focus on the relationship between gambling and masculinity. Gambling locations are studied and understood as facilitators of excess, while the life stories of pathological gamblers discussed. The paradoxical ambivalence of gambling practices is highlighted: on the one hand a form of domination of the subordinate classes, on the other an opportunity to resist through an anti-utilitarian act.
\end{abstract}

Keywords gambling, excess, ideology, masculinity, utilitarianism, pathological gambling

And every gambler knows that to lose Is what you're really there for (U2, Every Breaking Wave - In: «Songs of Innocence», 2014)

It is a cold winter afternoon in Rivolta D'Adda, a small town 30 kilometres west of Milan. Gianni is what the medical and psychological literature defines as a 'pathological gambler,' someone who is unable to resist the impulse to feed the slot machines. He is now in a clinic ward, the only one of this kind in Italy, where compulsive gamblers receive residential care for a 5-week period and are treated both pharmacologically and psychologically. He has agreed to tell me his story to aid my gambling research. 'After buying a bar,' he says, 'I started playing the [slot] machines. You keep playing, you keep playing. What happens to you then? When you lose, you want to recover [the money]. The more you gamble, the more you will gamble. It's a chain that has begun and doesn't end anymore.'

Gianni, aged 62, lives in a familiar context of substance abuse. His 34-year-old son is addicted to cocaine and alcohol; his wife is an alcoholic. Excess is a keyword defining his current state, an excess of financial losses due to gambling. He has been forced to close down his business, an excess of his addiction to a behaviour that is responsible for deteriorated relationships with family members. He is also a male, and as most literature on the 
topic shows, men are the most exposed to compulsive and pathological gambling - even if female addiction is rapidly growing.

This essay looks at male gambling not only by investigating it as a form of risk-taking behaviour, but also as a form of resistance to the utilitarian values which lie at the base of the market logic. Excess is viewed as a central notion in opposition to the notion of utility. Far from minimising the negative impact of excessive gambling on society and individuals, this contribution attempts to go beyond such an analysis based solely on the categories of pathology and expenditure. Through excess, the pathological gambler unveils the symbolic and arbitrary ideology of capitalism (Bjerg 2009) which sees economic success as a sign of election or a choice whereby money is used not as an investment or access to goods and services, but 'wasted.' What if this excessive behaviour were also a way to resist capitalistic and market values, such as capital accumulation and commodification of time? An answer might be found by investigating how excess manifests in male gambling practices.

To address these issues, I used two complementary ethnographic methods. Firstly, I conducted a three-month ethnographic observation in 23 gambling locations in Milan's metropolitan area, including Bingo halls, bars, tobacco shops, slot rooms and betting rooms, in an effort to understand how space enhances a spiral of excess. I then interviewed 10 male extreme gamblers (part of a larger sample including women) using a 'life-story approach' (Bertaux 1981), conducting non-directive dialogues with an unstructured outline and lasting between 1 and 2 hours each. The interviewees were selected from gamblers taking part in care pathways offering medical and/or psychological assistance in private or public structures. This allowed the categorisation as pathological gamblers in a scientific sense - the extreme degree of 'intensity' in a scale that comprises the recreational gambler (prone to perform the games as a social activity) and the problem gambler (the condition before the disease, where the player starts losing control over his behaviour) (American Psychiatric Association 2013; for further gambler typologies see Blaszczynski 2000, Lewy 1994, Reith 2007). The interviews focused on three main areas: (a) the 'education' of gamblers, in the broad sense of the persons, events and circumstances that led them to excessive gambling; (b) their concrete practices, ranging from gambling-related routine activities to the evolution of their 'career' through social, problem and pathological gambling; (c) the relationship between gambling and the personal and familial context; (d) finally, the reflexive sphere. The interviewees were asked to remember the period of their life affected by addictive behaviour in retrospect and to assess it in terms of future perspectives. ${ }^{3}$

The article attempts to answer the following research question: How does excess manifest in male gambling practices? Section 1 will analyse risk factors for extreme gambling with a particular focus on the relationship between gambling and masculinity. Section 2, in the effort to go beyond an analysis of gambling based solely on the categories of pathology and expenditure, will connect the phenomenon to the notion of excess. Gambling locations as facilitators of excess are the subject of Section 3, while

\footnotetext{
3 The research was partly funded by a not-for-profit organisation, Fondazione per la Sussidiarietà, which financed the ethnographic observation of gambling sites. The in-depth interviews were financed independently and the research was conducted between 2014 and 2017.
} 
Section 4 takes into consideration the life stories of pathological gamblers to show the concrete manifestations of excess in gambling behaviour. The last and conclusive Section will underline the paradoxical ambivalence of gambling practices, on the one side a form of domination of the 'really inferiors' (Nibert 2000), on the other an opportunity to resist through an anti-utilitarian act - wasting money.

Listening to male gamblers' views and experiences allowed me to come closer to the object of study and, more precisely, to the depths of excess in the lives of compulsive gamblers. In my opinion, even the impressive statistics on the phenomenon usually fail to achieve this goal, as they may be misleadingly used by the 'bank' (the state and the concessionaires) to support arguments that pathological gambling is under control and is statistically insignificant. On the contrary, this qualitative research meant that the researcher had to listen to the subjective meanings that gamblers ascribe to their behaviour and the huge consequences it has on their own lives, as well as those of their family members. These subjective histories are therefore better suited for the presentation of a portrait of gambling as an excess than the large amount of statistics generally used to describe the phenomenon.

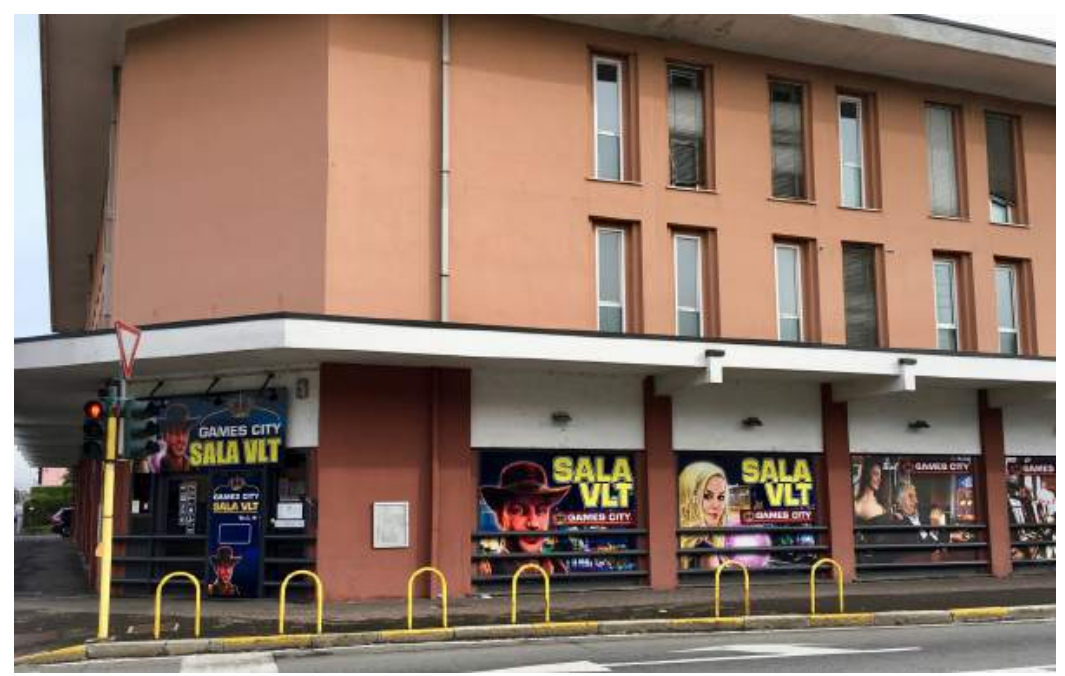

Figure 1. A video lottery store in Magenta, Milan metropolitan area. The store occupies the major part of the ground floor in a residential building close to the city hospital, a bus stop and a high school. The glasses are obscured with figures of the games (on the left) and stereotypical images of casino nightlife (on the right), such as a man smoking a cigar and playing a machine under the complacent gaze of a young woman.

\section{Gambling and Masculinity}

Problem and pathological gambling are the subjects of a wide medical, psychological and criminological literature, reinforcing the negative view of extreme gambling. The approaches rely on the notion of a pathological 'addiction,' a problem associated not only with massive and distorted use of a substance (drug or alcohol), but also with a 
behaviour repeated uncontrollably because it is dictated by an urgent and coercive need for satisfaction (Pani and Biolcati 2006). This form of addiction is characterised, from a clinical point of view, by compulsiveness due to the irresistible impulse to gamble, a loss of control and inability to limit the game, and a continuation of the gaming, despite the problems that it generates to the gambler.

Psychological studies of pathological gambling have mainly focused on predisposing factors, such as the presence of gamblers in one's family or tragic events, and by drawing an identikit of the hardest cases. The majority of these are men over 30 years old, unmarried, with little education and an early experience as gamblers (see Volberg 1996, Chalmers and Willoughby 2006; Dickson et al. 2008). However, definitive conclusions are difficult to formulate because the individual attitude to gambling is deeply influenced by socio-cultural variables. The player's profile can be very different from state to state. The correlation between pathological gambling and substance abuse has been equally investigated, and it is suggested that persons prone to substance addictions are more likely to gamble.

The very broad set of risk factors leading to addiction (Welte et al. 2004, Raylu and Oei 2002, Johansson et al. 2009) may be categorised into three main areas (Inserm 2008). The first includes the factors related to the subject of addiction, i.e. the type of game (the quicker the bet-to-pay interval, the higher the frequency and the risk), the initial gain (a high win leads to problem gambling), and the tools and context (for example, the anonymity and lack of social contact in online gaming are considered risk factors), as well as the offer and availability of games. Comorbid disorders such as alcohol and drug abuse (Spunt et al. 1998) also play a role in increasing extreme gambling behaviour. The second group includes environmental and context factors, ranging from cultural and religious (influence of obligations, religious restrictions) to economic and socio-educational ones (parents and family context, socio-economic status). Low levels of education may be linked to cognitive distortions, for example, an illusion of control, erroneous perceptions. Individual factors form the last area. These involve gender (Feigelman et al. 1995, Ladouceur et al. 1999, Volberg et al. 2001, Bondolfi et al. 2000), age (Shaffer and Hall 1996), as well as genetic and behavioural factors (Goudriaan et al. 2004, Walthers 2002) and the personal family and biography.

For our purposes, it is relevant to note that being a man is commonly recognised as a prominent risk factor. The number of male gamblers (whether social, problem or pathological) is higher than that of women in any inquiry into gambling diffusion, even if the female tendency to gamble is reportedly on the rise (Wardle et al. 2007, Abbott, Volberg and Ronnberg 2004, Davis and Avery 2004). The difference is also qualitative, as gender also seems to affect the choice of gambling type. Women prefer games of chance such as lotteries, slot machines and bingo (Grant and Kim 2002, Potenza et al. 2001), while men are over-represented in strategic games requiring skills (together with luck), such as poker or sports betting (Ibáñez et al. 2003, Wenzel and Dahl 2008, Ladd and Petry 2002).

The feminisation of gambling should not lead us to forget that men generally remain more likely than women to take part in gambling activities (Volberg 2003). Central to this is the role of space in the 'social construction' of gender (Umiker-Sebeok 1996). 
Many gambling sites are still gendered spaces populated mainly by men, a factor reinforcing and reproducing the gender distinctions that both gamblers and scholars take for granted. Sport-based games such as betting are often associated with male fandom, as in the case of football supporters (Raymen and Smith 2017).The development of online gambling has created new gendered environments with visual and social constructions empowered by ads and thematic magazines (see Jouhki, in this issue, on the hyperreal masculinity in online poker advertisement).

In acknowledging the state of the art of the literature on gambling and gender, I am fully aware of the feminist critique of problem gambling research (Mark and Lesieur 1992), which denounces the fact that the vast majority of studies has been conducted on male subjects and in male-dominated sites, as well as the fact that categorising male games as skill games may lead to an ideological interpretation of gender differences. When such skills are referred to, we implicitly mean 'male skills' or skills developed by male gamblers. For this reason, we make clear that the male universe is the subject of the research, and that its conclusions cannot be generalised to the female or total population.

\section{Gambling and Excess}

Gender is an important topic in contemporary gambling studies, not only given the underestimation of female gambling. Excess and utility, on the contrary, are not, or to be more precise, have been subsumed and then concealed by psychiatric and economic language, the former (excess) being referred to as problem, compulsive, or pathological gambling, and the latter (utility) reduced to the behaviour of the economic gambler, a person who plays with the rational intent of making profit. Excess is, according to the Cambridge Dictionary, 'an amount that is more than acceptable, expected, or reasonable.' An extent or amount which is immoderate and extreme, which goes beyond what is socially prescribed and results in what is proscribed or explicitly forbidden by shared values of a certain society, if not by formal norms. When used as a noun, it is synonymous with extra. Excess cannot be referred to without implying a connection to the extreme.

A better understanding of the notion of excess requires a brief consideration of what is usually understood to be its opposite, namely utility. After being recast in Darwinian evolutionism as the idea of survival utilities and in Marx's emphasis on useful labour as the mainspring of the human condition, the principle of utility remains of crucial importance in contemporary thought. Utilitarianism is a theory which considers the best action to be the one that is best able to maximise utility. It is based on Bentham's notion of utility as 'that property in any object, whereby it tends to produce benefit, advantage, pleasure, good, or happiness to prevent the happening of mischief, pain, evil, or unhappiness' (Bentham 1789, 2). According to Pawlett, the classical sociology of Marx, Durkheim and Weber, even while criticising utilitarian theory, did not break with the idea of slavery to utility and rationality as forces driving human action (Pawlett1997, 94). The principle of utility has not been radically challenged in contemporary mainstream sociology either, creating a juxtaposition between utility and excess where the latter notion is seen as a negative phenomenon to be contained. No example is more appropriate than the German sociologist Beck's analysis of excess in terms of 
calculation of risk and security (Beck1992). In coining the term 'risk society' he referred to dangers created by globalisation such as radioactivity, pollution and unemployment, issues capable of generating concern in people from all classes and, consequently, strategies to insulate oneself from these risks.

The contemporary age offers a variety of examples of the rise of excess. These are not confined to cases of extremism inspired by religion or ideology but instead are embodied in the everyday behaviour of people. They include the political populism which leads to the election of excessive leaders such as Donald Trump or an excessive and ultra-conservative reaction to socio-political problems (voting for Brexit or supporting xenophobic and anti-European parties). The excessive power of Internet oligopolies (Dean 2010) such as Facebook, Amazon and Google should also be mentioned, with their collection and ownership of an excess of data, a more apt term instead of the polite scientific language which calls the enormous amounts involved Big Data. Today's art market and the art auction world, providing an arena in which huge sums of money can be blatantly consumed (Crosthwaite 2011), offer another apt illustration of hyperbolic exaggeration.

'At times it has appeared,' Pawlett notes, 'that excess, rather than utility, has become the dynamic of contemporary social transformation, that the endless pursuit of utility has driven society into excess' (Pawlett 1997, 96). If we limit our argument to the examples listed above, it is no surprise that the supporters of Trump, Brexit and Marine Le Pen view the output of their favourite as rational definitions of economic and social issues. Due to the lack of concern shown by users when they provide information about themselves while pursuing personal utilities, including the construction and maintenance of social networks of friends and creating an appealing online persona to promote their own activities and skills, Facebook is allowed to act as 'the biggest surveillance-based enterprise in the history of mankind' (Lancaster 2017, 10). This is why 'utility and excess must not be conceived as binary oppositions, as mutually exclusive' (Pawlett 1997, 95).

Gambling is an apt terrain for an investigation of the controversial relationship between utility and excess. On the one hand, gambling is a phenomenon characterised by many nuances ranging from excess in problem and pathological gambling, to recreational activity, a socially acceptable behaviour. On the other hand, it highlights a moral definition of excess whereby gamblers who have 'lost control' are labelled as pathological, yet the term used by the state when increasing the possibility to gamble, through more games, more gaming sites and an increased frequency of extractions, is legalisation. Gambling, then, reveals that excess is declared or not depending on the agent who exceeds. I term this the social hierarchy of excess gambling. Losing is a noble action when performed by wealthy classes as a form of ostentatious expenditure through games of skill that assume that players are skilled, while it is ignoble when associated with lower socio-economic groups addicted to 'games of chance.'

According to Bataille's vision of excess, the modern calculation of utility is not able to provide a full sense of existing as a human being. The market economy acts as the ideological framework legitimating utility as a principle of social action; manifestations of excess are discouraged, if not explicitly limited. Bataille's attention focusses in 
particular on unproductive and profitless expenditure. In his influential essay, The Notion of Expenditure (Bataille 1985, 116-129), the French intellectual sees utility as theorised by classical approaches to be something to be aimed at because it provides pleasure, 'but only in a moderate form, since violent pleasure is seen as pathological' (ibid., 116). If this material pleasure is reduced to acquisition and conservation of goods, its role is that of a concession instead of a diversion. It is tolerated when productive, or at least when it does not conflict with productive and utilitarian needs. Non-productive expenditure is identified as the opposite of any rational consumption, and consequently denied and stigmatised. But, as 'human activity is not entirely reducible to processes of production and conservation' (Bataille 1985, 118), unproductive expenditure remains a part of the behaviour of any social agent.

Bataille's list of 'useless' activities includes 'luxury, mourning, war, cults, the construction of sumptuary monuments, games, spectacles, arts, perverse sexual activity (i.e., deflected from genital finality)' (Bataille 1985, 118). Unproductivity, in these examples, lies in the lack of ends and the enormity and irrationality of the loss. As to gambling, cited early by the author, 'the loss of insane sums of money is set in motion in the form of wagers' (Bataille 1985, 118), so that gamblers are led to losses disproportionate to their possessions. What they betray is the utilitarian faith in the principle of balanced accounts. This faith claims to compensate expenditure with acquisition. Excess gamblers destroy and do not create any capital, winning is merely a result either accidental or statistically unlikely action whose expected consequence is losing. The win is the apparent utilitarian goal of a process where economic rationale is achieved only from the perspective of the cashier, in line with the refrain 'the house always wins,' and not from that of the bettor. Fighting a perpetual battle to balance previous losses, 'players can never retire from the game' (Bataille 1985, 123) and are 'at the mercy of a need for limitless loss' (Bataille 1985, 118).

There is no doubt that unproductive expenditure may be viewed as functional if, in a sociological framework, it is interpreted as an ostentatious form of leisure class consumption (Veblen 1989). This is the type of gambling accurately described by Dostoyevsky in The Gambler, where the money wasted by the aristocracy and wealthy classes is a means of displaying their fortune. However, the rise of gambling in recent decades has mainly affected the middle and lower socio-economic groups, where the Veblenian-flavoured ostentatious loss is replaced by a different form of profitless expenditure. Such an excess represents, for these consumers of the entertainment industry, both a trap and a symbolic revolt. Many scholars and journalists denounce gambling as a trap because they claim that lower socio-economic groups are 'deceived' by a coalition between the State and commercial concessionaires. This alliance has created a market able to exploit the citizen's desire for social and economic redemption through the chance of a better life paid for by a scratch card or a coin inserted into a gaming machine. Actually, the word 'deception' risks becoming misleading here as it implies that these groups neither recognise nor understand the mendacity that lies at the base of the gaming industry, and the promise of a state of well-being that cannot be attained. It would be more correct to state that it is an ideological trap where gamblers continue to lose money and to take pleasure in it precisely because they know exactly the system works. As Kuldova points out, 'knowledge has very limited power to unsettle ideology' (Kuldova 2016, 99) and its efficiency in material and everyday practices. 
Gambling, in its extreme, compulsive and pathological forms, is also a revolt, it enhances a rebellion because it represents a direct challenge to the value of money and to the rational principles of the homo œconomicus.

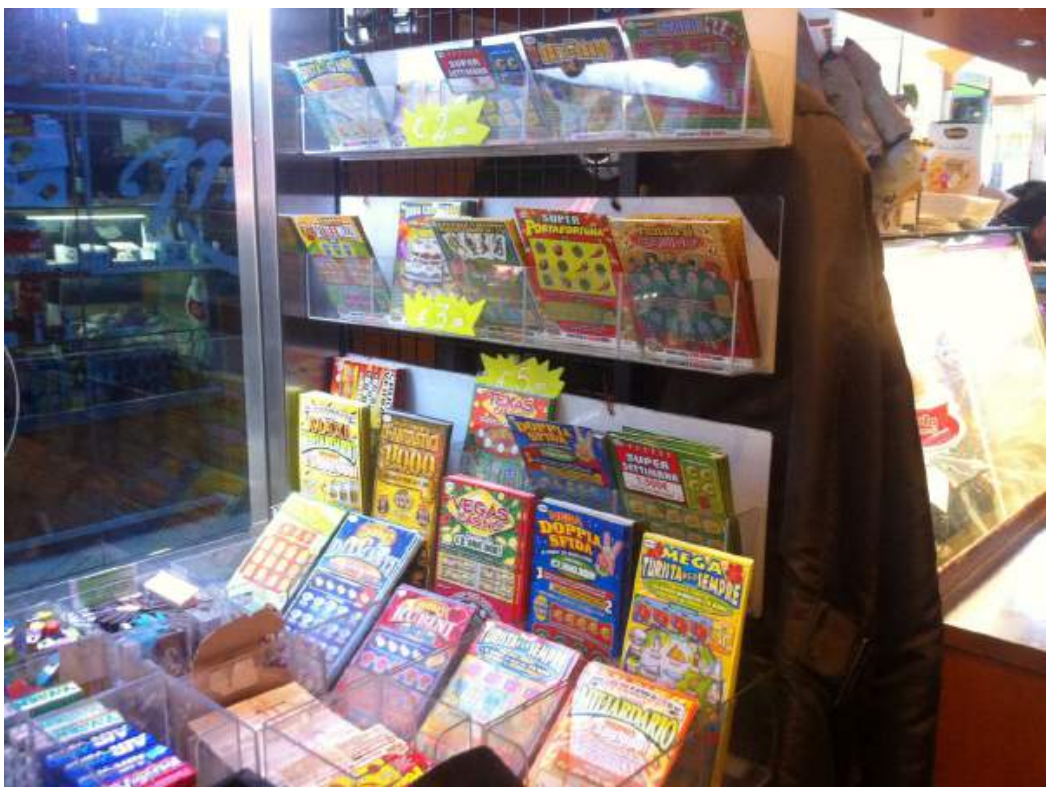

Figure. 2. A bar in the centre of Milan, close to Piazza Duomo. Scratch cards are displayed together with candies, with food offered nearby as another commodity good

\section{Places of Excess}

Excess gambling in the form of Bataille's non-productive expenditure takes place behind closed or partially closed doors (gambling halls, hidden corners of public bars). This spatial separation may support the idea that excess has disappeared from public space or at least that the designers of those spaces try to confine excess to a more private sphere. The word 'designer' is used here in the broad sense and includes those social agents who contribute to the establishment of both the structural features and the social meaning of the space. This means not only the gaming industry professionals responsible for the architecture of the rooms, the creation of gambling environments where both light and sounds are studied to lock the gambler in a timeless bubble, the design of the machines and the elaboration of the game schemes able to create a compulsive relationship between the individual and the machine (Schüll 2012), but also legislators who design regulations inspired by the protection of public health (for example, the placement of video lotteries in an area inaccessible to minors and separate from the non-gambling public, or the use of opaque glass to obscure the 'dangerous' behaviour from public view). Within the public space of a bar or a store, a private zone is created for compulsive games as slot machines, while what is perceived as 'recreational 
gambling' may take place in openly. The designers seem to be concerned that the privacy and habits of certain categories of gamblers are protected from scrutiny, and that the public role of a person does not include the exhibition of an addiction to machines. The boundary between the public and private realms, progressively removed over the last century (Sennett 1977), is artificially rebuilt by the gambling industry through the architecture of the space.

To have contact with gambling as a real phenomenon, we must first access gambling sites. With this in mind, I conducted a three-month ethnography in 23 Milanese locations where gambling took place to learn about the world of gamblers by observing their activities, and to assess to what extent space can enhance excessive behaviour. Despite the popular image of the bright nightlife in Las Vegas, the contemporary gambling industry generates its main profits not in casinos but through a ubiquitous and capillary urban network of shops and corners where gambling has become a daily activity rather than an occasional and adventurous escape. This example naturally excludes the new online gaming industry - a world that is not investigated in this essay, but that is a prominent part of contemporary gambling (Williams et al. 2012).

This landscape is a product of the progressive legalisation of gambling in most European states over the last 30 years. Its evolution in Italy may be divided into three phases (Pedroni 2014, 76-79). The first involved a drawn-out childhood period from 1946 with the launch of schedina, a popular prognostic game based on football matches, followed in the mid-80s by a restricted gambling industry and a clear distinction between gambling venues such as casinos and racecourses, and places of daily contact, bars and tobacconists for example, with little or no presence of games. The second phase may be termed the unruly adolescence. This period of maturation was characterised by legalisation and the progressive introduction of new games, including slot machines, video lotteries and online products, until the beginning of the $2010 \mathrm{~s}$. The Italian normative model which emerged from this process is characterised by a strong presence of the State as a regulator, even if gambling is actually managed by private concessionaries within a competitive and government-licensed market (Pedroni 2014, 71). This is in effect a perfect example of the neoliberal alliance between the State and private companies, where the search for a mutual benefit has shaped a legislation that other European countries are imitating. This is the premise of the third and more adult phase, whose maturity is visible both in the economic structure of gambling (a flourishing industry supported by a State interested in maximising fiscal revenues) and in the growing awareness of its social costs. The available data on incidence reveals that more than half $(54 \%)$ of the general population aged $15-74$ gamble at least once a year (Serpelloni 2013), while problem gamblers in Italy are estimated at between $1.3 \%$ and $3.8 \%$ of the population (767,000 to $2,296,000$ adults), and pathological gamblers vary from $0.5 \%$ to $2.2 \%$ (302,000 to 1,329000 persons) (Dipartimento Antidroga, 2015). Anti-gambling organisations and local administrations are pressuring for a public debate on (and against) gambling, and the first restrictive law (Balduzzi Decree) was presented by the Health Ministry in 2012 (Pedroni 2014, 78), accompanied by regional laws approved by 16 out of 21 Italian local authorities (19 regions and two autonomous provinces) and aimed at combating the proliferation of gambling sites. 


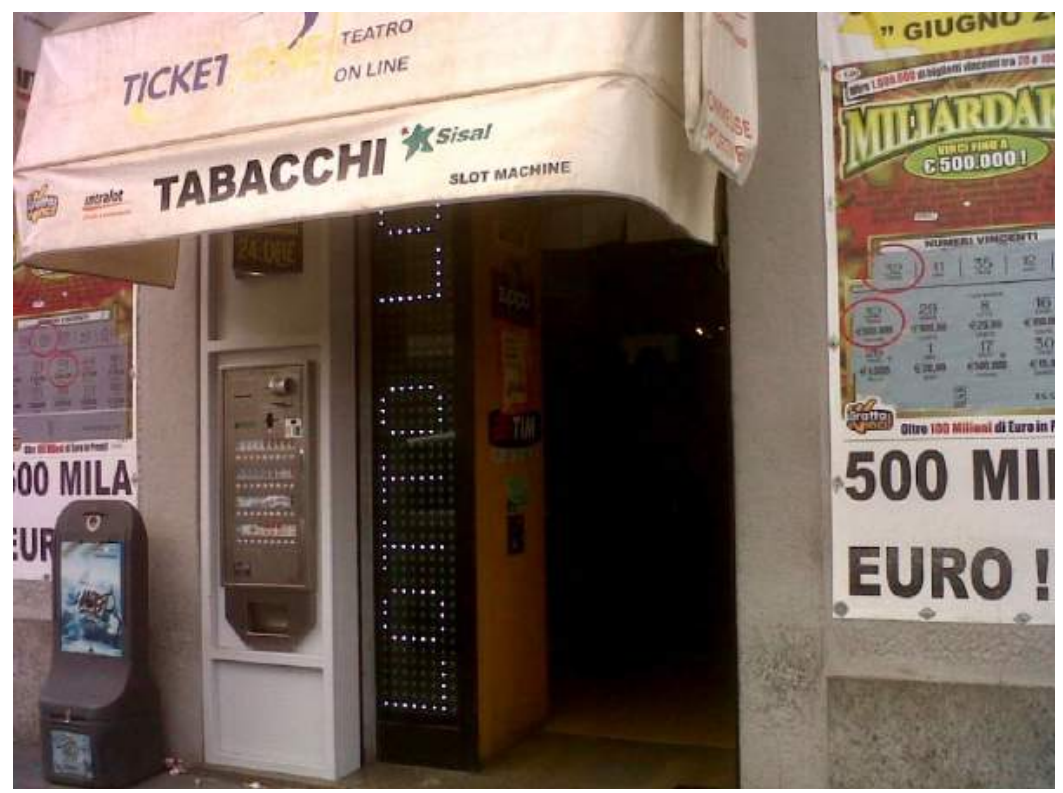

Figure 3. Entrance of a BT in Milan, Piazza Piemonte. The space is dominated visually by evidence of gambling, ranging from the names of concessionaries and products (Sisal, Intralot, Gratta\&Vinci) to two huge posters, on the left and on the right, claiming that a win of up to $€ 500,000$ is possible with a single scratch card.

Gambling has became an everyday presence in Italy, especially after the legalisation policies promoted by both centre-left and centre-right governments in the 1990s and in the 2000s, thanks to (or because of) two types of venues. Bars and tobacconists (BTs) are of the first type. Accessible to any member of the public, they are the most visible proof that gambling has become a ubiquitous phenomenon within consumer culture (Raymen and Smith 2017). The second are specialised outlets (SOs), such as Bingo halls, slot rooms and betting rooms, and are locations devoted exclusively to gambling and forbidden to minors. SOs do not contradict the trend towards the ubiquity and normalisation of gambling as a mainstream entertainment, since they are widely spread throughout both urban and rural areas. Far from being radically isolated from everyday reality, as casinos or racecourse are, they paradoxically make an escape from routine part of the daily experience. BTs licensed for the sale of games represent a hybrid environment in which the supply of food, beverages and tobacco is found side-by-side with a range of lotteries, scratch cards and bets. Upon entering a BT, I often noted that the visual elements related to gambling (ads, walls full of scratch cards, corners with slot machines etc.) were more prominently displayed than other goods and services sold by the shop. 'It is only later that one understands that the site is also a tobacco store', I wrote in one of my fieldnotes. 
It is true that SOs are recognisable from outside as sites for gambling, but at the same time it is not possible externally to know the details of what is happening inside. Dark glass facades and solid walls prevent citizens from seeing gamblers and their activities. This 'protection' means that passers-by are spared the sight of the actual gambling practices. However, such concealment creates an ideal environment for the excessive behaviour of whoever is inside the premises.

The differences between BFs and SOs may also be highlighted in the following five juxtapositions:

(a) BT disorder vs. SO maniacal order and cleanness. The former has an atmosphere of familiarity due to the coexistence of games, cafeteria and tobacco products, together with a sensory hyper-stimulation through screens and loudspeakers tuned to a radio or sound source. In the latter, the space is extensive and has been organised in order to avoid overlapping or confusion between rooms dedicated to gambling and the refreshments areas.

(b) The small spaces of a BT (with overlapping areas) vs. the expansive spaces of a SO. The spatial organisation in BTs requires consumers to interpret where the different closely placed services (gambling, food, tobacco) are, while SOs offer the freedom to circulate, inviting people to follow the shorter route to reach a specific product or service.

(c) BT naturalness vs. SO artificiality. The chaos in bars appears synonymous with a natural and spontaneous environment. The artificial lighting, cautious design, and consistency with the brand image of the particular gambling concessionaire make an $\mathrm{SO}$ a space separated completely from the flow of everyday life.

(d) BT noise vs. SO silence. An analysis of auditory stimuli underlines the contrast between the raised voices and normal, day-to-day confusion of BTs and the aseptic extra-ordinary dimension of SOs. Here, sounds such as coins won in the slot machines sometimes interrupt silence, but the background noises of city life are far away.

(e) BT mobility vs. SO stability: BTs are dynamic sites with consumers entering and leaving non-stop, while gamblers in an SO stay longer, move less and remain focused on one activity at a time.

This description is a necessary premise in order to clarify the spatial landscapes offered to gamblers, and to make some assumptions on how the spaces of gambling may favour excess and profitless expenditure. This seems to be possible in at least three ways. Firstly, BTs as highly diffused stores make gambling ubiquitous. They allow an everyday excess made of seemingly limited bets, whereby the regular monthly sum may be a considerable amount. For example, I observed during my research that it was common for many retirees to spend more than $€ 30$ on scratch cards every morning. Secondly, SOs are constructed behind walls where playing is possible without the activity being visible from the outside. Social stigma is reduced and the passing of time is not perceived in these artificial places. They become ideal places for cultivating excess, and are even more captivating when devoted to highly compulsive games such as slot machines and video lotteries. The third aspect is a transverse dimension to both categories. The adolescence of gambling noted above was characterised, among other features, by the diffusion of games with a higher pay-out frequency. Lotto extractions 
take place three times a week instead of weekly, 10eLotto extractions occur every five minutes, and scratch cards and slot machines can be played at any time for an instantaneous win. In short, the games introduced or modified in the last 30 years have produced a shorter interval between purchase and win/loss, and subsequently between the first purchase and the next.

Dependency, in the form of a compulsion to gamble, is facilitated both by the availability of everyday opportunities to gamble and by the contexts capable of creating a kind of space-time bubble, a player's isolation from the flow of daily life. This is particularly evident in the case of slot machines which are in an isolated location in the marginal areas of BTs and along the walls in SOs combined with structural features offering visual stimulation and the sound of coins falling during wins, capable of creating a complete immersive experience. During my visit to a video lottery terminal site, a 65-year-old man sitting in front of a machine and holding a glass full of coins said 'Call me at 11 o'clock, as I should go home to have lunch.' His request to the shop owner demonstrated an awareness of his incapacity to maintain control, and the possibility of losing temporal cognition.

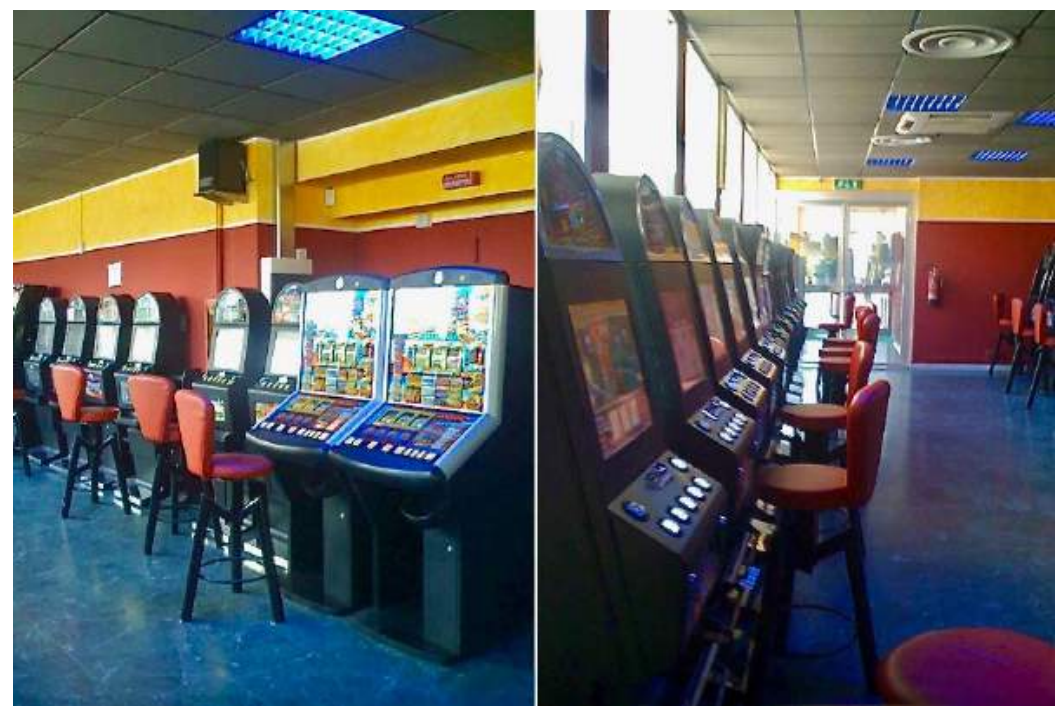

Figure 4. Slot machines and video lotteries in a Milanese gambling site, close to Viale Zara. Machines offering games defined as addictive are located in a separate room on the ground floor, while bingo (an example of recreational gambling usually not associated with the risk of addiction) is offered one floor higher.

\section{Biographies of Excess}

If we assume that the observation of gambling sites is able to provide elements to understand how space can act as a facilitator of excess, then in-depth interviews with pathological gamblers may better illuminate players' reasons and practices. Adrenaline 
is the most oft cited word used to describe the relationship between a gambler and games, and it is linked to both well-being, excitement and obsession.

If I don't play I don't feel well [laughs], it makes me feel good [...] The competition, the adrenaline rush when I see the results in front of me. As far as I am concerned, that is the reason to bet. (Fabio, M 48)

I liked playing because it was a challenge. (Edoardo, M 44)

This adrenaline rush is surprisingly not linked to a state of full enjoyment. The emotions observed in gambling sites, both positive and negative, are always moderate and controlled. 'When you win you feel satisfied, but not euphoric' (Fabio, M 48), and when one loses there is disappointment, not despair.

I have no happy memories of those afternoons in the bar, because I always left upset because whether you win or always lose, you are never happy. (Simone, M 63)

When I lost I felt a little bored, I wanted to change my life. I was so nervous and melancholic when I went home. (Raffaello, M 44)

In any interviewee's account there is a moment where a behaviour which appeared under control was subject to a progressive increase in frequency and number of bets, leading to a lack of control and a separation from reality.

I remember when I started, I was at the Cascina Gobba [tube station], where the machines are. I had stopped for a coffee [...] I paid with $€ 5$ and they gave me $€ 4$ change. There was someone playing the machines and I heard ti-ti-ti-ti-ti and all these coins fell out. I said to myself "Why not? What the Hell do I care, it's only €4." I put the money in, and a Bonus came up. I didn’t even know what it was. It gave me €200! I said "This is better than working", if this happens every day [...] I went to the bar, and cashed the $€ 200$ Bonus. I put it into my pocket, went home and felt satisfied with myself. The next day I left home and went again because I take the metro there every day. I saw the machine and changed $€ 50[\ldots]$ when I had finished I had won $€ 200$ plus what I had in my pocket, another $€ 150$. At that point I said to myself "Tomorrow I am coming earlier. I will give up work and come here." And that is how I started, coming every second day, and then I went somewhere else, and in the end a huge hole had formed. (Simone, M 63)

Similar stories mark the decline into excess gambling, an evolution which goes hand-inhand with an alienation of the player who becomes totally immersed in a parallel universe. 
I played the slots, I couldn't even tolerate someone standing behind me. I lived in another world and when I got home at night I was half mad, I didn't eat. (Simone, M 63)

I lost all my friends, especially in the end when I went out only to play. (Edoardo, M 44)

A player is alone [...] When you enter the world of gambling nothing else exists, you don't feel hungry, thirsty, you don't go to the toilet, don't drink, don't smoke... At that point you no longer exist, you're inside a shell. You play and that's all. (Attilio, M 54)

The dimension of excess appears to function as a separate realm, at least at the beginning of the pathological phase. Evidence can be found in interviewee's accounts describing the clear separation between every day and professional life, and the time devoted to gambling.

I went to work as normal, [but as soon as] I left work I had my routine appointment. (Simone, M 63).

I am a man people respect, I have 35 people who work for me and in 15 years I have never been accused of anything. But when I leave work I become another person. (Raffaello, M 44)

A man who plays games of chance is a man with three personalitieshis work persona, which is respected by his clients, [as well as] the man who gambles, $[. .$.$] and then there is the man who enters his home in$ the evening and has to account [to his family] for what he has done during the day. (Attilio, M 54)

However, in any story of excess gambling there comes a time when it is no longer possible to conceal the addiction, and the consequences for work and family begin to appear. The deterioration in family relationships ranges from the quality of everyday life ('When you gamble on-line you become one with the PC, with your smartphone, the TV, and therefore you have no time for your children nor your wife,' said Fabio, M 48) to separation from loved ones (the wife asks for a divorce, the children no longer speak to their father), not to mention lies and theft ('I asked my mother for her ATM card to collect her pension and I stole the money,' admitted Gianni, M 62. Similarly, Giorgio, M 57 said 'I was signatory on my mother's bank account, I took her money without telling her. Later I confessed because I was disgusted with myself.') These gamblers suffered from feelings of complete failure, and often regretted wasting their lives.

I threw away everything I have ever achieved as a man, as a carpenter, the faith everyone around me had in me. Perhaps I only imagine it, but I think that people now look at me very differently, I destroyed myself, I gambled away the chance to be a good father, which is what hurts most, I gambled away my chance to be a good husband. (Attilio, M 54). 
The economic consequences are devastating. Every interviewed, without exception, reported debts of thousands of euro, mainly with banks and financial companies, together with an accumulation of other debts with private individuals ('I get between 30 to 40 phone calls a day, from people who want money from me,' Raffaello, M 44). Loss of business is another frequent issue in interviewees' accounts.

We had a bar and we had to close because of the debts. (Gianni, M 62)

I am self-employed, I had a car transport business with my brother... The problem began with the financial crisis in 2008, up until then gambling was just a pastime. [I told myself] I was playing to recover the money. [...] It came to the point where my brother noticed that I was taking money that was not mine...it was the company's money. (Edoardo, M 44)

Excess gambling may also lead to health and psychological problems.

I was under so much stress that I had 2 heart attacks. (Gianni, M 62)

I also tried to kill myself, I was riding my motor bike and I closed my eyes. (Raffaello, M 44)

For the purposes of this study, a gamblers' relationship with money is of particular interest. Every interviewee remembered their fall into excess as strongly associated with a lack of control over money and its value. The inner logic of excess gambling lies exactly here - money is no longer perceived and used as money. Gamblers are far beyond over-spending in an unproductive manner. The sums they spend/invest in gambling are undeniably disproportionate to their incomes. Moreover, a return to gambling after a significant loss does not serve the purpose of only recovering money, but rather that of rebalancing the account with the 'fates'. The rational part of the gambler perfectly knows he has no statistical chance of winning against the bank, but his need for excess keeps him gambling.

[I understood I had gone too far] when I ran out of money! [laughs] Because when you are at it you don't notice how much money you are spending, not even when it is $€ 150$ a day... The money has no value for you. There is no specific moment [when you understand you have lost control]. When you are immersed in it, it is as if you have been caught by an avalanche and you can't fight your way out. (Fabio, M 48)

I remember one day that I had gone to finish up a job, and they paid me $€ 1,000$. On the way home I found a gambling hall, I won $€ 900$ with $€ 30 \ldots$ I then went to the video lotteries and I lost everything... proof that I had lost all control. And then I had to pay a supplier and borrow the money to pay him. (Gianni, M 62) 
I spent more than half of my salary. (Simone, M 63)

I have had winnings of $€ 3,000,4,0005,000$, and in three days I had nothing left... if I had $€ 100$ in my pocket I wasted $€ 100$, if I had $€ 1,000$ in my pocket I would have wasted $€ 1,000$. (Edoardo, M 44)

You never get the money back; you keep falling till you hit rock bottom. (Simone, M 63)

The biographies I collected illustrate a recurring process where economic problems, once discovered by family members, lead to a familiar crisis. In parallel, the gambler is no longer able to hide his addiction from colleagues or employers, because the excess gambling begins to affect his performance in the workplace. Family and work complications make it obvious to the gambler that he has lost the control he thought he had over his gambling, and that a therapeutic pathway is needed to recover his social relationships. What I have described in few lines is a process which develops over many years, a period during which the gambler becomes familiar with excess through the negation of the value of the money he has spent in an unproductive manner. This is an implicit negation of the utilitarian values which characterise a productive and capitalist society, one where profitless activities are regarded as dysfunctional for individuals and society as a whole.

\section{Extreme Losers}

Both excess and excessive gambling are cultural constructs where the definition is largely indebted to an epistemology of disease and disorder (Reith 2007, 37) as used in psychiatry. In fact, the term 'pathological gambler' was introduced by the American Psychiatric Association in its 1980 Diagnostic and Statistical Manual of Mental Disorder (DSM-III, followed by two successive editions, DSM-IV and DSM-V), and is connoted by the presence of a set of 'symptoms' and measured through diagnostic tools.

Excess is an activity which may also have a further significance for our purposes. In Baudrillard's interpretation, excess is the result of the proliferation of the ideology of utility (Pawlett 1997, 197pp), a kind of reaction to the sovereignty of functional obligations.

Ours is a society founded on proliferation, on growth which continues even though it cannot be measured against any clear goals. An excrescential society whose development is uncontrollable, occurring without regard for self-definition, where the accumulation of effects goes hand in hand with the disappearance of causes. The upshot is gross systemic congestion and malfunction caused by hypertelia - by an excess of functional imperatives, by a sort of saturation. (Baudrillard 1993, 31).

In biology, hypertely is an extreme overdevelopment of an organ which then becomes disadvantageous and damaging to the animal concerned, an exaggerated degree of 
growth not explainable by utility. Baudrillard coined hypertelia to describe the excessive degree of consumption and production not based on utility and observed within contemporary societies, where our needs and the objects we purchase to meet them are no longer related through their usefulness.

The paradox of excess gambling is grounded in its two-fold nature of entertainment and of reaction to utilitarianism. Gambling expanded within liberalised markets and became a mainstream leisure activity for consumers (Reith 1999, 2013). It is also a response or backlash to the hypertelic profit and utilitarian mentality. Whereas the utilitarian ideology prescribes useful and profitable activities, to invest money despite the evident statistical probability of loss is an act of resistance to the values of utilitarian and capitalistic society. Gambling may therefore be seen as a perfect example of the 'insubordinate function of free expenditure' in Bataille's words (Bataille 1985, 129), as well as a form of sovereignty of the Self over social constraints. This sovereignty, which 'constitutes the region formally exempt from self-interested intrigues to which the oppressed subject refers as to an empty but pure satisfaction' (Bataille 1985, 148), reveals the unwillingness to submit oneself to the household economy through a feeling of superiority, a moment where instead of serving life, life serves the individual. Curiously, excess gambling particularly demonstrates its potential as a tool of sovereignty in the most recent advertisement campaigns promoted by Italian gambling concessionaries, where the used keywords are 'safety' and 'responsibility' - an attempt by the industry to distance itself from the negative image of gambling (Pedroni 2016, Pedroni 2017). Consumers find it difficult to trust current marketing trends which present 'a whole series of products deprived of their malignant property: coffee without caffeine, cream without fat, beer without alcohol' (Žižek 2004) and gamblers do not believe in gambling without risk, nor the 'decaffeinated' representations offered by advertising. On the contrary, they are eager to experience passion through excess and risk where individual forces are liberated in a state of excitation, rational laws of calculation are substituted by pseudo-rationality, unproductive values are created. Though it may seem a paradox, one true within the realm of intellectual argument and not linked with the reality of gambler behaviour, gambling functions as a liberation from the constraints of a market economy, where individuals are dominated. Pathological gamblers fail as citizens because they are not able to grasp the chances of personal growth offered by society, as husbands and parents because they cannot take care of their families, as consumers because they are unable to enjoy gambling as merely a form of pleasure and entertainment just as the commercial industry of gambling invites them to do. However, in extreme gambling, where money is no longer money (Bjerg 2009, Raymen and Smith 2017), a new sphere of action is created, excitation is freed and the illogical becomes logical.

The rational choice model underlying utilitarianism states that individual actions are the consequences of a motive. In line with this, excess gambling is irrational and, which is the same, immoral, both for an industrial society where it stands as an example of an unproductive activity, and a post-industrial consumerist one where the dysfunctional gambler fails as a consumer. The difference lies in the attitude toward recreational gambling, which is tolerated in the latter but not in the former. Despite this, one might argue that the excessive gambler is the ultimate consumer. As the only thing a gambler does is consume, their behaviour is in fact harmful to consumer society because they 
overspend rapidly to the point of bankruptcy, while the ideal consumer maintains an ability to spend over time.

A seductive image of a process to describe excess gambling is that of creative destruction, not in the economic sense of a process of industrial mutation that revolutionises the economic structure from within (Schumpeter 2013), but as a desire to remove what came before in order to set up what will come next. Such a tension of opposing experiences, destructive and creative is typical of modernism (Harvey 1990, 10-13), and seems to act as the perversion of excessive gambling. An extreme behaviour destroys wealth, through endless losses, to create the illusion of a world ruled by non-utility laws. The interviewees illustrate this well when their debts have caused the failure of a family company or they have brought about their own destruction through non-stop slot machine gaming.

An approach oriented to viewing excessive gambling as an act of sovereignty also leads to a reconsideration of the notion of utility. Players appear to derive a form of pleasure while immersed in the act of gambling, despite the evidence of economic losses. This activity is deemed useless if utility is measured in terms of the (catastrophic) consequences of the gambler's behaviour, but has a usefulness if we take into consideration the utility of the whole process (Le Menestrel 2001). Gambling, in fact, may provide social rewards (Binde 2009, 16-18), such as prestige, in specific contexts where the excessive player measures themselves with other gamblers and, in Goffman's dramaturgical terms, attempts to favourably impress others by demonstrating skill (Goffman 1969).

Masculine gambling, when excessive, creates an extreme loser, one who is devoted to an expenditure so profitless and useless that money has no longer meaning as such, it is merely a medium to experience excess. Gambling has been often read as a mechanism of a social domination (Volberg and Wray 2007) and a tool for mass distraction and a relief valve for subordinate classes (Nibert 2000). What if a further function of gambling is a form of resilient consumption in which socially oppressed or marginalised individuals and groups may experience freedom, breaking the social constraints linked to utilitarian values by denying them through an extremely unproductive expenditure? Following Bataille's lexicon once again, such a function may be viewed in terms of a (momentary) recovery of sovereignty, where a compulsive, addictive, profitless, exaggerated (in short, excessive) session of gambling acts as a means to control the forces to which gamblers are submitted. Marginalised victims of neoliberal capitalism, economic failures unable to attain the material success they desire, they regain sovereignty through the destruction of economic capital. If money is, from a Marxist standpoint, the ultimate foundation of any social relationship and the goal of any productive activity, its destruction serves the double purpose of dismantling one's network ties and of denying capitalistic values, as clearly testified by the interviewees' biographies collected in this essay. Here lies the contradictory nature of gambling - the compulsive loss of control as defined under the psychiatric approach becomes, in the topsy-turvy world of gamblers, a way to take control by challenging the rules to which they feel subjugated in the utilitarian realm. When conceptualising gambling as submission, guilt and anxiety, the interviewees are expressing a retreat from an exceptional state of sovereignty and, through medical and psychological care, they are 
regaining a condition of 'normality' where their past behaviour can only appear inappropriate. The rebellion and sovereignty are now in the past.

Abbott, Max, Rachel Volberg, and Sten Rönnberg. 2004. "Comparing the New Zealand and Swedish National Surveys of Gambling and Problem Gambling." Journal of Gambling Studies 20: 237- 258.

American Psychiatric Association. 1994. Diagnostic and Statistical Manual of Mental Disorders: Fourth edition. Washington, DC: American Psychiatric Press.

American Psychiatric Association. 2013. Diagnostic and Statistical Manual of Mental Disorders: Fifth edition. Washington, DC: American Psychiatric Association.

Bataille, Georges. 1985. Visions of Excess: Selected Writings 1927-1939. Minneapolis: University of Minnesota Press.

Baudrillard, Jean. 1993. The Transparency of Evil: Essays on Extreme Phenomena. London: Verso.

Beck, Ulrich. 1992. Risk Society: Towards a New Modernity. London: Sage.

Bentham, Jeremy. 2007 [origin. edn. 1789]. An Introduction to the Principles of Morals and Legislation. Mineola (NY): Dover Publications.

Binde, Per. 2009. Gambling Motivation and Involvement: A Review of Social Science Research. Swedish National Institute of Public Health. Accessed November 16, 2017. https://dspace.ucalgary.ca/bitstream/1880/51055/1/R2009-20-gamblingmotivation-a-review.pdf.

Blaszczynski, Alex. 2000. "Pathways to Pathological Gambling: Identifying Typologies". Electronic fournal of Gambling Issues 1: 1-14.

Bondolfi, Guido, Christian Osiek, and François Ferrero. 2000. "Prevalence Estimates of Pathological Gambling in Switzerland." Acta Psychiatrica Scandinavica 101: 473-475.

Chalmers, Heather, and Teena Willoughby. 2006. "Do Predictors of Gambling Involvement Differ Across Male and Female Adolescents?" Journal of Gambling Studies 22 (4): 373-392.

Grosthwaite, Paul. 2011. "What a Waste of Money: Expenditure, the Death Drive, and the Contemporary Art Market." New Formations 72: 80-93.

Davis, Diane Rae, and Lisa Avery. 2004. "Women Who Have Taken Their Lives Back from Compulsive Gambling: Results from an Online Survey." Fournal of Social Work Practice in the Addictions 4: 61-80.

Dean, Jodi. 2010. Blog Theory: Feedback and Capture in the Circuits of Drive. Cambridge: Polity.

Dickson Laurie, Jeffrey L. Derevensky, Rina Gupta. 2008. "Youth Gambling Problems: Examining Risk and Protective Factors." International Gambling Studies 8 (1): 25-47.

Dipartimento Antidroga. 2015. Relazione annuale al Parlamento sullo stato delle tossicodipendenze in Italia. Dipartimento per le politiche antidroga, Presidenza del Consiglio dei Ministri. Accessed May 1, 2017. http:// www.politicheantidroga.gov.it/attivita/pubblicazioni/relazioni-al-parlamento/ relazione-annuale-2015/presentazione.aspx.

Dostoevsky, Fyodor. 1996 [origin. edn. 1867]. The Gambler. Mineola (NY): Dover Publications. 
Feigelman, William, Paula H. Kleinman, Henry R., Robert B. Millman, and Martin L. Lesser. 1995. "Pathological Gambling Among Methadone Patients." Drug and Alcohol Dependence 39: 75-81.

Goffman, Erving. 1969. Where the Action Is. London: Allen Lane.

Goudriaan, Anna E., Jaap Oosterlaan, Edwin de Beurs, and Wim Van den Brink. 2004. "Pathological Gambling: A Comprehensive Review of Biobehavioral Findings." Neuroscience and Biobehavioral Reviews 28 (2): 123-141.

Grant, Jon E., and Suck Won Kim. 2002. "Gender Differences in Pathological Gamblers Seeking Medication Treatment." Comprehensive Psychiatry 43: 56-62.

Harvey, David. 1990. The Condition of Postmodernity: An Enquiry into the Origins of Cultural Change. Oxford: Blackwell.

Ibáñez, Angela, Carlos Blanco, Paula Moreryra, and Jerónimo Sáiz-Ruiz. 2003. "Gender Differences in Pathological Gambling." The fournal of Clinical Psychiatry 64 (3): 295-301.

Inserm. 2008. Feux de hasard et d'argent. Contextes et addiction. Contextes et addictions. Paris: Les éditions Inserm. Accessed October 1, 2017 . http:// lesrapports.ladocumentationfrancaise.fr/BRP/084 000697/0000.pdf.

Johansson, Agneta, Jon E. Grant, Suck Won Kim, Brian L. Odlaug, and K. Gunnar Götestam. 2009. "Risk Factors for Problematic Gambling: A Critical Literature Review." fournal of Gambling Studies 25 (1): 67-92.

Jouhki, Jukka. 2017. "The Hyperreal Gambler: Notes on the Visual Construction of Men in Online Poker Ad". Journal of Extreme Anthropology, Online First: 10.5617/ jea. 5441

Kuldova, Tereza. 2016. "Directing Passions in New Delhi's World of Fashion: On the Power of Ritual and 'Illusions without Owners"'. Thesis Eleven 133 (1): 96-113.

Ladd, George, and Nancy M. Petry. 2002. "Gender Differences Among Pathological Gamblers Seeking Treatment." Experimental and Clinical Psychopharmacology 10: 302-309.

Ladouceur, Robert, Normand Boudreault, Christian Jacques, and Frank Vitaro. 1999. "Pathological Gambling and Related Problems Among Adolescents." Journal of Child and Adolescent Substance Abuse 8: 55-68.

Le Menestrel, Marc. 2001. "A Process Approach to the Utility for Gambling". Theory and Decision 50 (3): 249-262.

Lewy, Richard. 1994. "Existe-t-il un profil psychosociologique du joueur?" Les Cahiers Espaces 38: 145-158.

Mark, Marie E., and Henry R. Lesieur. 1992. "A Feminist Critique of Problem Gambling Research." Addiction 87 (4): 549-565.

Nibert, David A. 2000. Hitting the Jackpot: Government and the Taxing of Dreams. New York: Monthly Review Press.

Pani, Roberto, and Roberta Biolcati. 2006. Le dipendenze senza droghe. Lo shopping compulsivo, Internet e il gioco d'azzardo. Turin: Utet.

Pawlett, William. 1997. "Utility and Excess: The Radical Sociology of Bataille and Baudrillard." Economy and Society 26 (1): 92-125.

Pedroni, Marco. 2014. "The 'Banker' State and the 'Responsible' Enterprises: Capital Conversion Strategies in the Field of Public Legal Gambling". Rassegna Italiana di Sociologia 55 (1), $71-98$. 
Pedroni, Marco. 2016. "Much More than a Game: The Role of Commercial Advertising in the Struggle between the Advocates and Opponents of Gambling". In Clashing Wor(l)ds: From International to Intrapersonal Conflict, edited by Anthony Ocaña, 83-96. Oxford: Inter-disciplinary.

Pedroni, Marco. 2017 (in press). "Let Me Dream with the Betting Sheet in my Hand": Gambling Advertising Narratives and the Destigmatisation of Gamblers". In Communication and Conflict in Multiple Settings, edited by Peter Bray and Marta Rzepecka. Leiden: Brill.

Potenza, Marc N., Marvin A. Steinberg, Susan D. McLaughlin, Ran Wu, Bruce J. Rounsaville, and Stephanie O'Malley. 2001. "Gender-related Differences in the Characteristics of Problem Gamblers Using a Gambling Helpline" American Fournal of Psychiatry 158: 1500-1505.

Raylu, Namrata., and Tian P.S. Oei. 2002. "Pathological Gambling: A Comprehensive Review." Clinical Psychology Review 22: 1009-1061.

Reith, Gerda. 1999. The Age of Chance: Gambling and Western Culture. London: Routledge.

Reith, Gerda. 2003. Gambling: Who Wins? Who Loses? New York: Prometheus.

Reith, Gerda. 2007. "Gambling and the Contradictions of Consumption: A Genealogy of the 'Pathological' Subject". American Behavioral Scientist 51 (1): 33-55.

Schüll, Natasha D. 2012. Addiction by Design: Machine Gambling in Las Vegas. Princeton (NJ): Princeton University Press.

Schumpeter, Joseph A. 2013. Capitalism, Socialism and Democracy. London: Routledge.

Sennett, Richard. 1977. The Fall of Public Man. New York: Alfred A. Knopf.

Serpelloni, Giovanni. 2013. Gambling. Gioco d'azzardo problematico e patologico, inquadramento generale, meccanismi fisiopatologici, vulnerabilità, evidenze scientifiche per la prevenzione, cura e riabilitazione. Dipartimento per le politiche antidroga, Presidenza del Consiglio dei Ministri. Accessed March 31, 2017. http:// www.politicheantidroga.it/media/587792/manualegambling_light.pdf.

Shaffer, Howard J., and Matthew N. Hall. 1996. "Estimating the Prevalence of Adolescent Gambling Disorders: A Quantitative Synthesis and Guide toward Standard Gambling Nomenclature.” Journal of Gambling Studies 12: 193-214.

Spunt, Barry, Ida Dupont, Henry Lesieur, Hilary J. Liberty, and Dana Hunt. 1998. "Pathological Gambling and Substance Misuse: A Review of the Literature." Substance Use and Misuse 33: 2535-2560.

Umiker-Sebeok, Jean. 1996. "Power and Construction of Gendered Spaces." International Review of Sociology 6 (3): 389-403.

Veblen, Thorstein. 1899. The Theory of the Leisure Class: An Economic Study in the Evolution of Institutions. Basingstoke: Macmillan.

Volberg Rachel A., and Matt Wray. 2007. "Legal Gambling and Problem Gambling as Mechanism of Social Domination? Some Considerations for Future Research." American Behavioral Scientist 51 (1): 56-85.

Volberg, Rachel A. 1996. "Prevalence Studies of Problem Gambling in the United States." Fournal of Gambling Studies 12 (2): 111-128.

Volberg, Rachel A. 2003. "Has There Been a 'Feminization' of Gambling and Problem Gambling in the United States?" Fournal of Gambling Issues 8. Accessed November 10, 2017. http://jgi.camh.net/index.php/jgi/article/view/3619. 
Volberg, Rachel A., Max W. Abbot, Sten Ronnberg, and Ingrid M.E. Munck. 2001. "Prevalence and Risks of Pathological Gambling in Sweden." Acta Psychiatrica Scandinavica 104 (4): 250-256.

Walters, Glenn D. 2002. "Behavior Genetic Research on Gambling and Problem Gambling: A Preliminary Meta-analysis of Available Data." Fournal of Gambling Studies 17: 255-271.

Wardle, Heather, Kerry Sproston, Jim Orford, Bob Erens, Mark Griffiths, Rebecca Constantine, and Sarah Piggot. 2007. British Gambling Prevalence Survey 2007. London: HMSO.

Welte, John W., Grace M. Barnes, William F. Wieczorek, Marie-Cecile Tidwell, and John C. Parker. 2004. "Risk Factors for Pathological Gambling." Addictive Behaviors 29 (2): 323-335.

Wenzel, Hanne, and Alv Dahl. 2008. "Female Pathological Gamblers: A Critical Review of the Clinical Findings." International fournal of Mental Health and Addiction 7: 190-202.

Williams, Robert J., Robert T. Wood, and Jonathan Parke, eds. 2012. Routledge International Handbook of Internet Gambling. London: Routledge.

Žižek, Slavoj. 2004. "Passion in the Era of Decaffeinated Belief". The Symptom 5 (4). Accessed November 10, 2017. http://www.lacan.com/passionf.htm.

Marco Pedroni is Associate Professor of Sociology of Culture and Course Coordinator BA Communication Sciences, at the School of Law, eCampus University, Italy. Contacting author: marco.pedroni@uniecampus.it More: about.me/marcopedroni 